\title{
Study of Wear on the Metal on Polycarbonate Urethane (PCU) Contact in Total Hip Arthroplasty Using Finite Element Method
}

\author{
Wahyu Dwi Lestari ${ }^{1, *}$ Luluk Edahwati $^{1}$ Ndaru Adyono $^{1}$ Rifky Ismail $^{2} \mathrm{~J} \mathrm{Jamari}^{2}$
}

Athanasius Priharyoto Bayuseno ${ }^{2}$

\author{
${ }^{1}$ Department of Mechanical Engineering, Faculty of Engineering, University of Pembangunan Nasional Veteran Jawa \\ Timur, 60294, Indonesia \\ ${ }^{2}$ Department of Mechanical Engineering, Faculty of Engineering, Diponegoro University, 50275, Indonesia \\ *Corresponding author. Email: wahyu.dwi.tm@upnjatim.ac.id
}

\begin{abstract}
Latterly, the polycarbonare urethane (PCU) has suggested a viable substitude to conventional bearings. The aim of this study is to determine the von Mises stress and contact pressure as a function of different of acetabular cup thickness. The analysis of this study was conducted by the finite element method. Six variation of acetabular liner thickness $(5 \mathrm{~mm}$, $10 \mathrm{~mm}, 15 \mathrm{~mm}, 20 \mathrm{~mm}, 30 \mathrm{~mm}$, and $40 \mathrm{~mm}$ ) were used in this simulation. The contact pressure was determined to predict the wear performance of PCU acetabular liner. The result shown that the thicker of the acetabular liner, the smaller the contact pressure and the smaller the contact radius. Thus predictable that the thinner the PCU acetabular liner, the higher the wear rate.
\end{abstract}

Keywords: PCU, Contact Pressure, Von Mises Stress, FEM.

\section{INTRODUCTION}

Total hip arthroplasty (THA) through acknowledge the most prosperous medication carried out in patients from elders to teenagers. More severe activities in patients receiving hip arthroplasty cause friction moments and higher wear rates [1-2]. Along with the increasing friction activity on the bearing surface resulting in an increase in temperature which is a danger aspect for implant strength in the lifelong [3]. As a result, greater friction can cause aseptic loosening of implants in the medium, as well as long-term complications. [4-5]. Thus, reducing friction becomes important for the longterm survival of hip arthroplasty [3].

Since surgeons' major goal is implant long-term survival, there have been significant advancements in implant design, bone fixation implants, and bearing surfaces throughout the past half-century [6]. To prevent wear debris, which might cause an immunological reaction and lead to aseptic easing, it's critical to use a bearing surface with a low wear rate. The bearing surface has undergone numerous changes since THA's inception. However, the polyethylene bearing surface remains a mainstay in THA systems, and its application continues to expand [7]. The primary issue with THA's primary action on polyethylene bearing surfaces is osteolysis, a condition caused by polyethylene wear debris that can result in aseptic loosening and premature implant failure [8]. The wear of polyethylene is a multifactorial biotribological activity. Earlier reports have proposed kinematics [9]-[13], part orientation [14]-[16], design of implant [17-18], the wear laws of material [19]-[21], joint loads [22-23] and the anatomy and demography of patient [24-25] as prospective aspects supporting to polyethylene wear.

Minimizing friction between bearing surfaces is very important to ensure long-term survival of THA [3]. In recent years, the production of $80 \mathrm{~A}$ polyurethane bionate has proposed a viable substitute to bearing components. Biostability and excessive endurance to hydrolysis, oxidation, and calcification have been shown in vitro [26]. Three years of follow-up, in vivo reports have shown that there are the lack of noticeable signs of biodegradation in PCU material [27]. Over millions of loading cycles, a comparison of metal on PCU with metal on highly cross linked polyethylene (including gamma 
irradiation) revealed that polyurethane had a reduced wear rate, better corrosion protection, and wear debris particles that are less likely to cause osteolysis. [28]-[31]. All of these features that makes polyurethane a suitable alternative for a THA bearing surface.

The development of bearing surface wear must be understood accurately as a critical performing index of the artificial hip joint. Implant performance can be assessed by measuring the level of wear through clinical and laboratory studies [32]. Essner et al. [33] performed a hip simulator test exhausting a abridged loading cycle, and competed and evaluated wear on ceramics on PE, metals on metals and ceramics on ceramics artificial hip joint for a brief time of up to 5 million cycles. Such in vitro tests are mostly expensive and time-consuming, especially when various design parameters are required.

The finite element method (FEM) as a prevailing computational device has been generally operated to develop the construct of artificial hip joint and to reduce the costly experimental tests. The FEM has become the approach of option to investigate the mechanical performance of substances described by complex forms and which are exposed to complexx loading. As such, it is extensively employed in the analysis of contact between solids [33]-[36]. Using the FEM, a number of research have been carried out to better understand the contact stresses, deformation, destruction, and malfunction of prosthesis. [37][38]. Maxian et al. [39] The wear and damage layout of a soft UHMWPE cup were modelled. Teoh et al. [36] prolonged the Maxian's model and performed a parametric wear simulation of UHMWPE liner surfaces by reflecting the elasto-plastic characteristics of the material. Bevil et al. [40] simulated the effect of several design parameters on volumetric wear and penetration depth of a soft UHMWPE liner surface, such like radial clearance, head size, and liner thickness. Matsoukas et al. [41] and Kang et al [42] implement a 3D FEM by integrating cross shear and both creep laws. The majority computational wear assessment stated above concentrated on the wear of soft acetabular liner (UHMWPE) surfaces which articulate against a femoral head. Our previous research used FEM to determine the influence of surface texturing on the UHMWPE flat surface contacted with steel balls against von misses stress and contact pressure [43]-[45].

Research of PCU on metal pairs as a component of artificial hip joints has been in demand by several researchers in recent years. Based on a literature search, there is very limited study of FEM PCU material as a bearing material in artificial hip joints. This study presents a simulation of FEM PCU material as a bearing material contacted with steel as a femoral head. The phenomenon observed is contact pressure and von misses, where this data will be used to predict the wear value that occurs in the bearing material. FEM simulation is done by applying six variations in the thickness of the bearing material.

\section{METHOD}

The artificial hip joint as being arranged of a rigid femoral head and an elastic acetabular liner. The type of simulation used in this study is axisymmetric simulation. Axisymmetric simulation is a simulation in which the geometry model has symmetry with its rotation axis. A parametric 2D axisymmetric FEM of a metal on PCU (hard on soft) total hip arthroplasty was acquired applying ABAQUS. Acetabular liner and femoral head modeling in this study can be seen in Fig. 1. The load given to the femoral head is $2500 \mathrm{~N}$ in the direction of the positive $\mathrm{y}$ axis, and modeled as a perfectly rigid body. The acetabular liner with PCU material was persumable linear elastic. In this simulation is no fluid film lubrication applied between femoral head and acetabular liner. Material properties of PCU and steel were uses in this simulation is presented in Table 1 .

Table 1. Mechanical characteristics of contact surface

\begin{tabular}{lcc} 
Material & Young Modulus (Mpa) & Poisson's Ratio \\
\hline Steel & 210000 & 0.29 \\
PCU & 20 & 0.5 \\
\hline
\end{tabular}

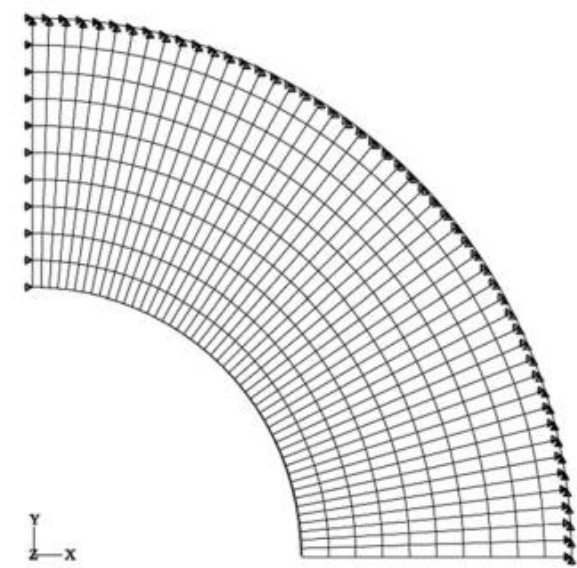

Figure 1 Axisymetric model of femoral head and acetabular liner

The interaction between both the femoral head and the acetabular cup was generated using the penalty approach and the traditional isotropic Coulomb friction model. The contact discretization was done on a surface to surface basis. The first boundary condition is given to the outside of the acetabular liner, where this boundary condition is encastre ( $U x, y=0, \operatorname{Rux}, y=0)$, which means there is no displacement and rotation in that area. While the second boundary condition is given to the reference point of the femoral head. The second boundary condition used is a type of displacement in the direction of the $\mathrm{x}$ axis and rotation of the $\mathrm{x}$ and $\mathrm{y}$ axis, which means that the reference point at the femoral head is only 
allowed y axis. Furthermore the acetabular cup was meshed with the CAX4R type quadrilateral element, with 500 elements. Meshing is only given to acetabular liners, because the femoral head is assumed to be rigid body. The model projected of paper regarding on the hypothesis that the acetabular cup is infinetely thick. Six different thicknesses of acetabular liner were employed in this investigation to better understand the impact of thickness on contact pressure $(5 \mathrm{~mm}, 10 \mathrm{~mm}, 15 \mathrm{~mm}, 20 \mathrm{~mm}, 30$ $\mathrm{mm}, 40 \mathrm{~mm}$ ).

\section{RESULT AND DISCUSSION}

Before the FEM simulation PCU material is carried out prior validation to ensure that the simulation steps taken are correct. The validation was carried out by distinguishing with the work of Tudor [46] that are presented in Figure 2. Verification was applied for $5 \mathrm{~mm}$ thickness. The contact pressure at the contact surface as a function of the contact radius is concurrence with the outcome of Tudor. It can be seen that the simulation results are close to the research performed by Tudor with an error percentage below $5 \%$. Thus it can be said that the simulations carried out are valid and can proceed to further research.

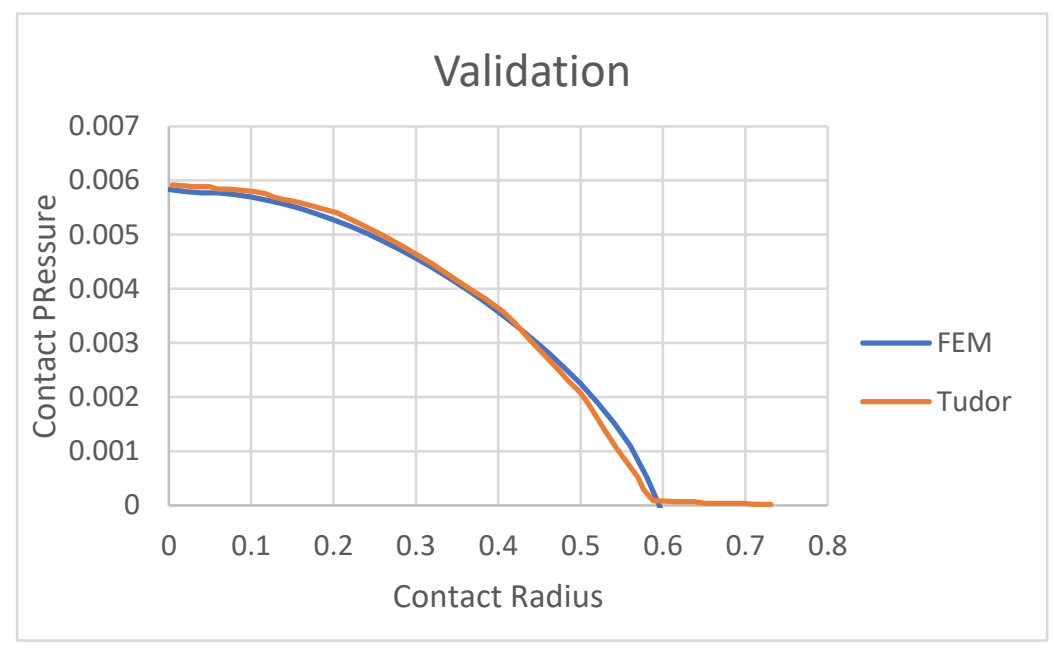

Figure 2 Validation of contact pressure from the FEM simulation with the journal Tudor for a thickness of $5 \mathrm{~mm}$ liner

The results of a finite element simulation of hip arthroplasty using the new PCU soft bearing surface are presented in this research. Figure 3 depicts the contact pressure distribution for the six examples. The thicker the acetabular liner, the lower the contact pressure and the smaller the contact radius, as shown in the graph of simulation results. PCU contact pressure material simulation results for thickness variations are shown in Figure 4 . The amount of wear value can be predicted by the contact pressure value $(\mathrm{Cp})$. A model approach to describing wear is proposed by Archad [47]. Archad supposes that the serious parameters in sliding wear are the stress area in contact and the relation sliding distance between the contact surfaces. According to Archad's wear model, it is known that if the contact pressure value increases, the wear rate increases. Based on the results of the simulations that have been made, it is known that the thicker the acetabular liner, the smaller the contact pressure value. Thus it can be predicted that the thinner the PCU acetabular liner, the higher the wear rate.

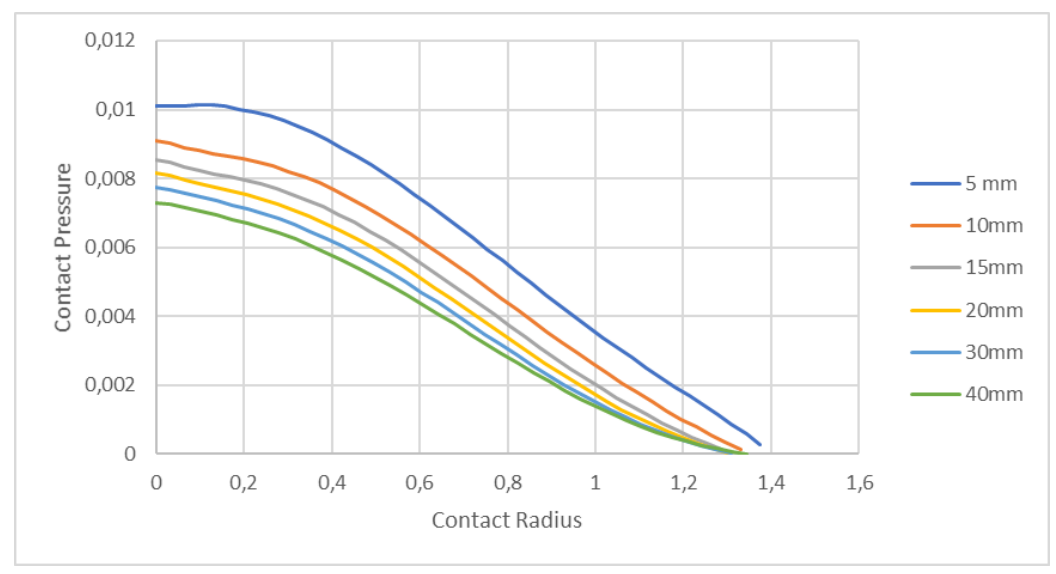

Figure 3 Contact pressure distribution for six cup thickness (the diameter of femoral head $\mathrm{d}=22 \mathrm{~mm}$, joint load $\mathrm{F}=2500 \mathrm{~N}$, and relative clearance $\psi=0.005$ ) 


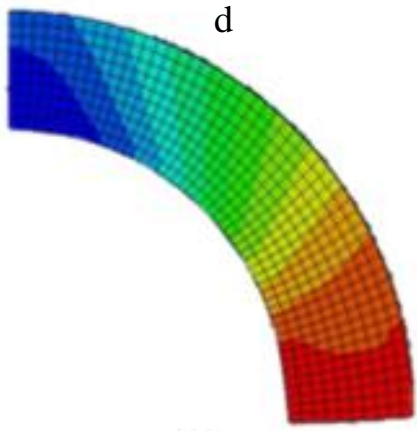

a

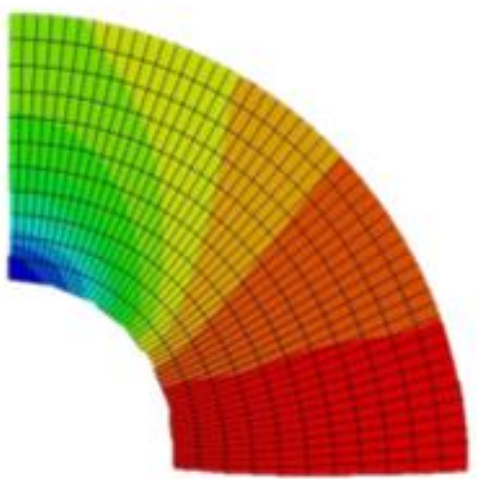

d

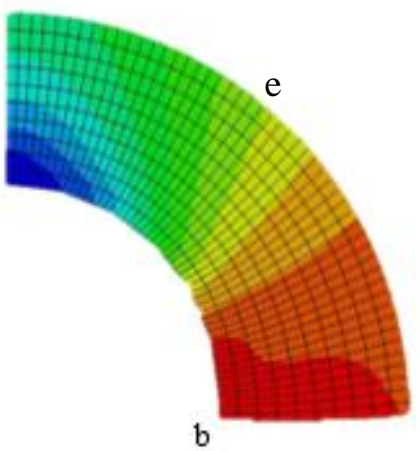

b

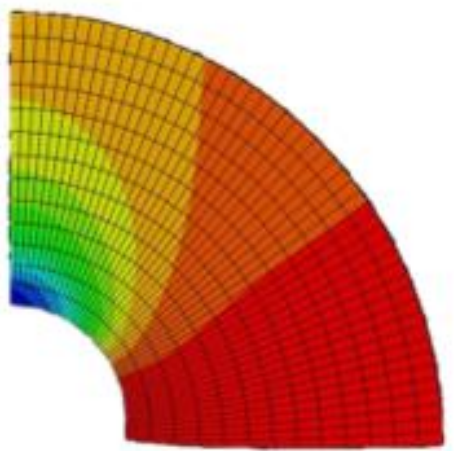

e

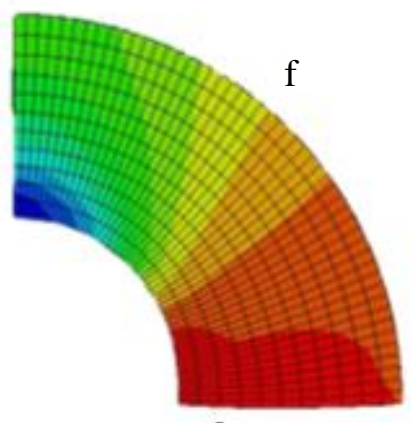

c

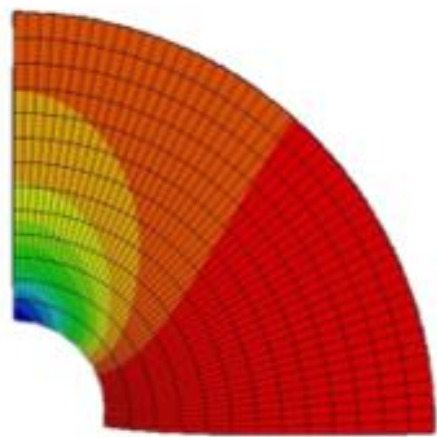

f

Figure 4 The 3D plot of the contact pressure simulation results for thickness (a) $5 \mathrm{~mm}$, (b) $10 \mathrm{~mm}$, (c) $15 \mathrm{~mm}$, (d) 20 $\mathrm{mm}$, (e) $30 \mathrm{~mm}$, and (f) $40 \mathrm{~mm}$

In addition to contact pressure data, von Mises stress data was also taken in this study. Von Mises stress value obtained from PCU metal on contact simulation is mentioned in Figure 5. Based on the picture analyzed that at a thickness of $5 \mathrm{~mm}$ to $30 \mathrm{~mm}$ the thinner the acetabular liner the greater the value of von Mises stress. Von Mises value decreased slightly in the $40 \mathrm{~mm}$ acetabular liner thickness. 3D plot of von Mises for each acetabular liner thickness shown in Figure 6.

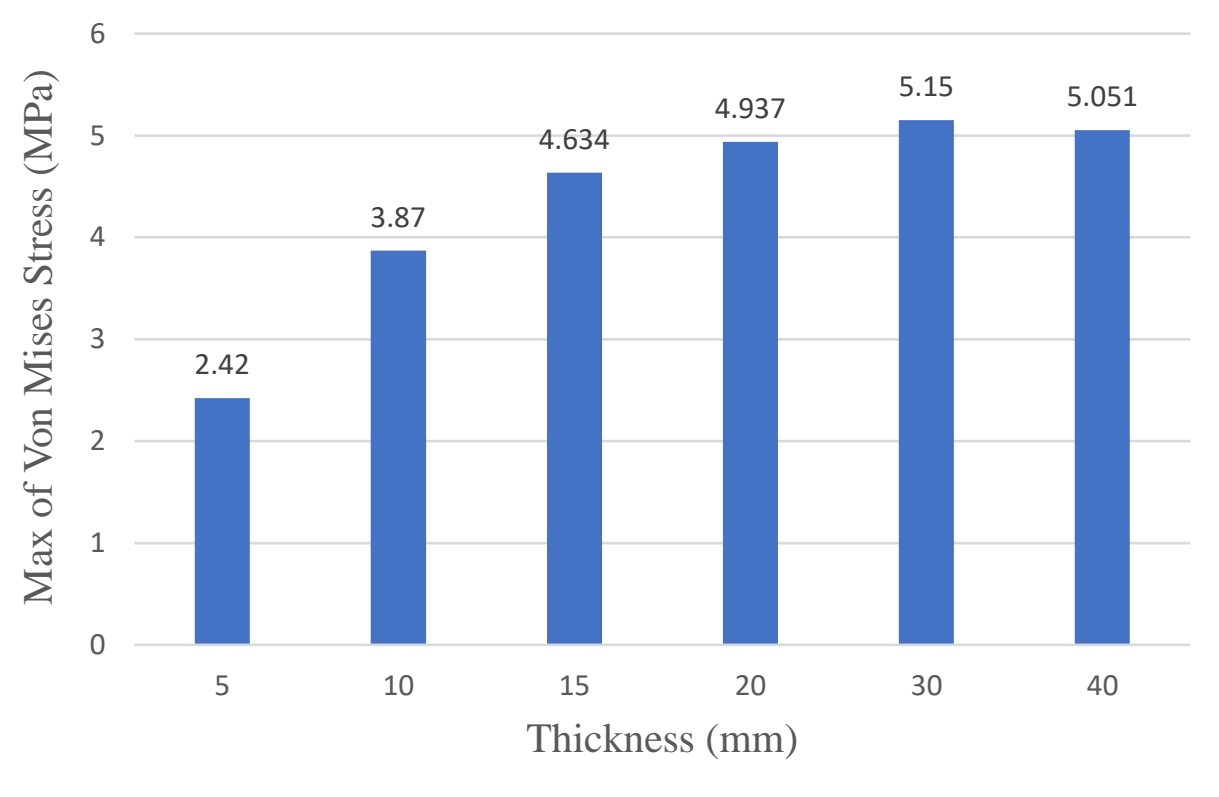

Figure 5 The von Misses stress distribution as a function of different thickness of PCU acetabular liner 


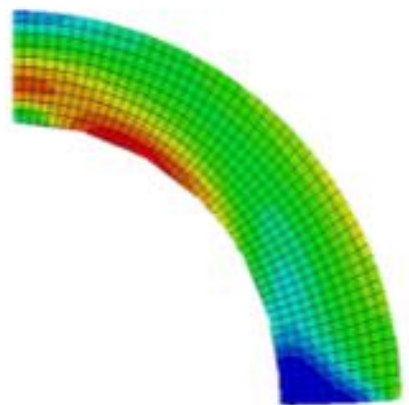

a

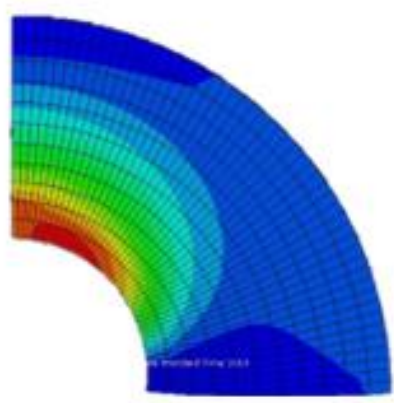

d

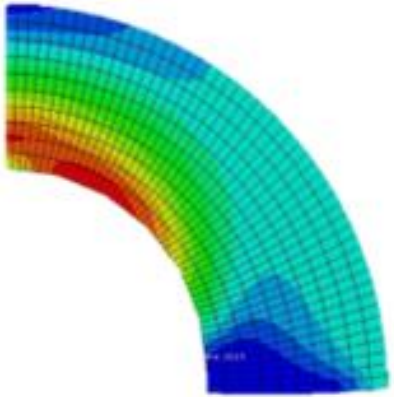

b

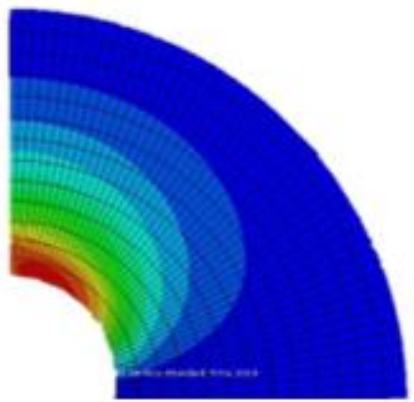

$\mathrm{e}$

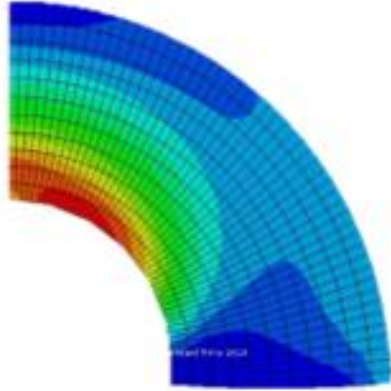

c

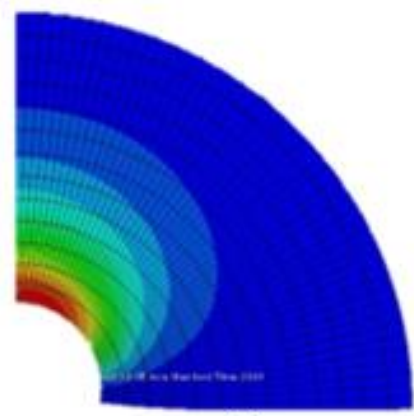

f

Figure 6 The three dimensional von Mises stress distribution for (a) 5mm, (b) 10mm, (c) 15mm, (d) 20mm, (e) $30 \mathrm{~mm}$, and (f) $40 \mathrm{~mm}$ thickness variation of PCU acetabular liner

\section{CONCLUSION}

This paper reports a finite element method to calculate the contact pressure and von Mises stress for soft on hard hip implants. The FEM model may be operated for prosthesis construct, surgery preparing, and patient retrieval programs. The thickness of acetabular liners made from PCU has an influence on contact pressure, which directly affects the value of material wear when contact occurs. Increased contact pressure has a negative impact because it increases the value of wear in the artificial hip joint. As conclusion from the obtained results, the thicker of the acetabular liner, the smaller the contact pressure and the smaller the contact radius. Thus predictable that the thinner the PCU acetabular liner, the higher the wear rate.

\section{REFERENCES}

[1] T. Stu, H. Brenner, W. Puhl, and K. Gu, "Sports activities 5 years after total knee or hip arthroplasty: the Ulm Osteoarthritis Study," Ann. Rheum. Dis., vol. 64, n, pp. 1715-1720, 2005.

[2] U. R. C. Hatterji, M. A. R. K. J. A. Shworth, P. E. L. L. Ewis, and P. E. J. D. Obson, "Effect of total hip arthroplasty on recreational and sporting activity," ANZ J. Surg., vol. 74, n, pp. 446-449, 2004.
[3] P. Damm et al., "Friction in Total Hip Joint Prosthesis Measured In Vivo during Walking," PLoS One, vol. 8, no. 11, pp. 1-8, 2013.

[4] G. B. Flugsrud, L. Nordsletten, B. Espehaug, L. I. Havelin, and H. E. Meyer, "The effect of middle-age body weight and physical activity on the risk of early revision hip arthroplasty A cohort study of 1 , 535 individuals," Acta Orthop., vol. 78, no. 1, pp. 99-107, 2007.

[5] H. Malchau, P. Herberts, P. Soderman, and A. Oden, "Prognosis of Total Hip Replacement. The Swedish national hip arthroplasty registry," 2000.

[6] W. H. Harris, "The First 50 Years of Total Hip Arthroplasty," Clin. Orthop. Relat. Res., vol. 467, pp. 28-31, 2009.

[7] S. S. Liu and J. J. Callaghan, "Are Trends in THA Bearing Surface Continuing to Change? 2007-2015 Usage in a Large Database Cohort," J. Arthroplasty, vol. 32, pp. 3777-81, 2017.

[8] J. A. J. Broom et al., "The Relationship Between Polyethylene Wear and Periprosthetic Osteolysis in Total Hip Arthroplasty at 12 Years in a Randomized Controlled Trial Cohort," J. Arthroplasty, vol. 32, pp. 1-6, 2016.

[9] M. A. Wimmer, M. M. Ardestani, and P. P. Amena, "Prediction of Polyethylene Wear Rates from Gait 
Biomechanics and Implant Positioning in Total Hip Replacement," Clin Orthop Relat Res, vol. 475, pp. 2027-2042, 2017.

[10] D. Bennett, L. Humphreys, S. O. Brien, C. Kelly, J. Orr, and D. E. Beverland, "The Influence of Wear Paths Produced by Hip Replacement Patients during Normal Walking on Wear Rates," J. Orthop. Res., vol. 26, no. September, pp. 1210-1217, 2008.

[11] S. Budenberg et al., "Contact surface motion paths associated with leg length inequality following unilateral total hip replacement," Proc IME H J Eng Med, vol. 226, no. 12, pp. 968-974, 2012.

[12] S. M. Davey, J. F. Orr, F. J. Buchanan, J. R. Nixon, and D. Bennett, "The effect of patient gait on the material properties of UHMWPE in hip replacements," Biomaterials, vol. 26, pp. 49935001, 2005.

[13] F. Liu, J. Fisher, and Z. Jin, "Effect of motion inputs on the wear prediction of artificial hip joints," Tribiology Int., vol. 63, pp. 105-114, 2013.

[14] J. M. Elkins, J. J. Callaghan, and T. D. Brown, "The 2014 Frank Stinchfield Award The 'Landing Zone' for Wear and Stability in Total Hip Arthroplasty Is Smaller Than We Thought: A Computational Analysis," Clin Orthop Relat Res, vol. 473, pp. 441452, 2015.

[15] J. G. Haw, A. K. Battenberg, D. T. Huang, and T. P. Schmalzried, "Wear Rates of Larger-Diameter Cross-Linked Polyethylene at 5 to 13 Years : Does Liner Thickness or Component Position Matter?," J. Arthroplasty, vol. 32, no. 4, pp. 1381-1386, 2017.

[16] N. J. Little, C. A. Busch, J. A. Gallagher, C. H. Rorabeck, and R. B. Bourne, "Acetabular Polyethylene Wear and Acetabular Inclination and Femoral Offset," Clin Orthop Relat Res, vol. 467, pp. 2895-2900, 2009.

[17] P. F. Lachiewicz, E. S. S. Bsn, and J. M. Martell, "Wear and Osteolysis of Highly Crosslinked Polyethylene at 10 to 14 Years: The Effect of Femoral Head Size," Clin. Orthop. Relat. Res., vol. 474, pp. 365-371, 2016.

[18] M. P. Siljander, E. A. Baker, K. C. Baker, M. R. Salisbury, C. C. Thor, and J. J. Verner, "Fretting and Corrosion Damage in Retrieved Metal-onPolyethylene Modular Total Hip Arthroplasty Systems : What Is the Importance of Femoral Head Size ?," J. Arthroplasty, vol. 33, no. 3, pp. 931-938, 2018.

[19] L. Kang, A. L. Galvin, Z. M. Jin, and J. Fisher, "A simple fully integrated contact-coupled wear prediction for ultra-high molecular weight polyethylene hip implants," Proc IME H J Eng Med, vol. 220, pp. 33-46, 2006.

[20] L. Kang, A. L. Galvin, T. D. Brown, J. Fisher, and Z. Jin, "Wear simulation of ultra-high molecular weight polyethylene hip implants by incorporating the effects of cross-shear and contact pressure," Proc IME H J Eng Med, vol. 222, pp. 1049-1064, 2008.

[21] L. Mattei, F. Di Puccio, and E. Ciulli, "A comparative study of wear laws for soft-on-hard hip implants using a mathematical wear model," Tribiology Int., vol. 63, pp. 66-77, 2013.

[22] V. Kralj-iglic and R. Kos, "Polyethylene Wear is Related to Patient-specific Contact Stress in THA," Clin Orthop Relat Res, vol. 469, pp. 3415-3422, 2011.

[23] G. Matziolis, L. Krakow, F. Layher, K. Sander, J. Bossert, and S. Brodt, "Patient-Specific Contact Stress Does Not Predict Polyethylene Wear Rate in a Specific Press fit Cup," J. Arthroplasty, vol. 32, pp. 3802-3805, 2017.

[24] J. Gallo, V. Havranek, and J. Zapletalova, "Risk factors for accelerated polyethylene wear and osteolysis in ABG I total hip arthroplasty," Int. Orthop., vol. 34, pp. 19-26, 2010.

[25] T. P. Schmalzried and O. L. Huk, "Patient Factors and Wear in Total Hip Arthroplasty," Clin Orthop Relat Res, no. 418, pp. 94-97, 2004.

[26] I. Khan, N. Smith, E. Jones, D. S. Finch, and R. Elizabeth, "Analysis and evaluation of a biomedical polycarbonate urethane tested in an in vitro study and an ovine arthroplasty model . Part I : materials selection and evaluation," Biomaterials, vol. 26, pp. 621-631, 2005.

[27] I. Khan, N. Smith, E. Jones, D. S. Finch, and R. Elizabeth, "Analysis and evaluation of a biomedical polycarbonate urethane tested in an in vitro study and an ovine arthroplasty model . Part II : in vivo investigation," Biomaterials, vol. 26, pp. 621-631, 2005.

[28] R. A. Smith, A. Maghsoodpour, and N. J. Hallab, "In vivo response to cross-linked polyethylene and polycarbonate-urethane particles," J. Biomed. Mater. Res. Part A, pp. 227-234, 2009.

[29] S. M. Kurtz, R. Siskey, and M. Reitman, "Accelerated aging, natural aging, and small punch testing of gamma-air sterilized polycarbonate urethane acetabular components," J. Biomed. Mater. Res. B Appl. Biomater., vol. 93, n, pp. 442-447, 2010. 
[30] J. J. Elsner et al., "Wear rate evaluation of a novel polycarbonate-urethane cushion form bearing for artificial hip joints," Acta Biomater., vol. 6, no. 12, pp. 4698-4707, 2010.

[31] M. Gupta, "Evaluation of the wear performance of a polycarbonate-urethane acetabular component in a hip joint simulator and comparison with UHMWPE and cross-linked UHMWPE," J. Biomater. Appl., vol. 27(I), pp. 55-65, 2012.

[32] H. Sieber, C. B. Rieker, and P. Köttig, "Analysis of 118 second generation metal-onmetal retrieved hip implants," J. Bone Jt. Surg. Br., vol. 81, pp. 46-50, 1988.

[33] S. M. Kurtz, J. A. Ochoa, C. V White, S. Srivastav, and J. Cournoyer, "Backside nonconformity and locking restraints affect liner / shell load transfer mechanisms and relative motion in modular acetabular components for total hip replacement," $J$. Biomech., vol. 31, pp. 431-437, 1998.

[34] S. M. Kurtz, L. Pruitt, C. W. Jewett, R. P. Crawford, D. J. Crane, and A. A. Edidin, "The yielding, plastic flow, and fracture behavior of ultra-high molecular weight polyethylene used in total joint replacements," Biomaterials, vol. 19(21), pp. 19892003, 2003.

[35] T. Laurian and A. Tudor, "Some aspects regarding the influence of the clearance on the pressure distribution in total hip joint prostheses," Ann. Univ. “"Dunarea Jos”, Galati, vol. 1(1), pp. 393-7, 2003.

[36] S. H. Teoh, W. H. Chan, and R. Thampuran, “An elasto-plastic finite element model for polyethylene wear in total hip arthroplasty," J. Biomech., vol. 35(3), pp. 323-330, 2002.

[37] R. K. Korhonen, A. Koistinen, Y. T. Konttinen, S. S. Santavirta, and R. Lappalainen, "The effect of geometry and abduction angle on the stresses in cemented UHMWPE acetabular cups - finite element simulations and experimental tests," Biomed. Eng. Online, vol. 14, pp. 1-14, 2005.

[38] A. C. Cilingir, "Finite Element Analysis of the Contact Mechanics of Ceramic-on-Ceramic Hip Resurfacing Prostheses," J. Bionic Eng., vol. 7, no. 3, pp. 244-253, 2010.
[39] T. A. Maxian, T. D. Brown, D. R. Pedersen, and J. J. Callaghan, "Adaptive Finite Element Modeling of Long-Term Polyethylene Wear in Total Hip Arthroplasty," J. Orthop. Res., vol. 14 (41), pp. 668-675, 1996.

[40] S. L. Bevill, G. R. Bevill, J. R. Penmetsa, A. J. Petrella, and P. J. Rullkoetter, "Finite element simulation of early creep and wear in total hip arthroplasty," J. Biomech., vol. 38, pp. 2365-2374, 2005.

[41] I. Y. Kim, M. Hall, and S. Street, “Total Hip Wear Assessment: A Comparison Between Computational and In Vitro Wear Assessment Techniques Using ISO 14242 Loading and," $J$. Biomech. Eng., vol. 131, no. April 2009, pp. 1-11, 2016.

[42] L. Kang, A. L. Galvin, J. Fisher, and Z. J. Ã, "Enhanced computational prediction of polyethylene wear in hip joints by incorporating cross-shear and contact pressure in additional to load and sliding distance : Effect of head diameter," J. Biomech., vol. 42, pp. 912-918, 2009.

[43] W. D. Lestari, F. H. Priyoga, J. Jamari, and A. P. Bayuseno, "Numerical Modelling of Surface Texturing of UHMWPE under Influence of Normal Load,” Mater. Sci. Forum, vol. 864, pp. 8-12, 2016.

[44] W D Lestari, R Ismail, J. Jamari, and A. P. Bayuseno "Investigation of the Influence of Shapes-Texture on Surface Deformation of UHMWPE as a Bearing Material in Static Normal Load and Rolling Contact," IOP Conf. Ser. Mater. Sci. Eng., 2017.

[45] W. D. Lestari, J. Jamari, and A. P. Bayuseno "The Von Mises Stress Distribution on the Surface of UHMWPE with Texture-Shaped Variation in the Presence of Normal Load and Dry Sliding Contact," AIP Conf. Proc., vol. 020055, 2017.

[46] A. Tudor, T. Laurian, and V. M. Popescu, "The effect of clearance and wear on the contact pressure of metal on polyethylene hip prostheses," Tribiology Int., vol. 63, pp. 158-168, 2013.

[47] J. F. Archard, "Contact and Rubbing of Flat Surfaces,” J. Appl. Phys., vol. 24, p. 981, 1953. 